\title{
Relato sobre la experiencia cultural de mujeres mayangnas en el uso del para o tunidor y el langlang en el tratamiento ancestral de la corteza del árbol de tunu'
}

\section{Organización de Mujeres Mayangnas (MYRAB)}

El tunu (tuno en español) es un árbol forestal de uso cultural y económico milenario de los mayangnas. Se trata de una de las tantas especies que se encuentran en la reserva de biosfera BOSAWAS y cuya mayor existencia se ubica en el territorio Mayangna Sauni As. La convivencia con esta especie de árbol y la biodiversidad de BOSAWAS representa el buen vivir para nuestro pueblo. Es prácticamente un símbolo con un importante valor histórico para nosotras, algo cuyos usos y conocimientos provienen directamente de nuestros ancestros. Su uso es variado tanto en la elaboración de vestimenta, como en lo doméstico, la caza y para cargar herramientas y animales.

La extracción de la corteza del tunu era -y lo es todavía para nosotras- una actividad muy importante para la continuidad de la cultura de nuestro pueblo. Desde los primeros tiempos de esta actividad artesanal se sabía exactamente en qué época se podía extraer con facilidad su corteza. Los ancestros recomendaban el invierno como el tiempo adecuado para su extracción (descortezar), debido a que la corteza estaba más suave entonces. Por el contrario, si la actividad se realizaba en verano se recomendaba extraer el tuno de las vegas de los ríos, ya que la humedad existente en estas áreas mantenía suave su corteza. Para la extracción de la corteza de esta árbol se preparaban herramientas ancestrales elaboradas en madera: el para o tunidor y el langlang.

\section{Proceso ancestral de selección del árbol y extracción de su corteza}

Las etapas del proceso ancestral utilizado hasta hoy para la extracción de la corteza del tunu son las siguientes:

1. Se inicia con la selección del árbol. La escogencia se hace según su tamaño: mientras más pequeño, más fácil la extracción de su corteza (descortezar). Antes de cortar se elige el lado del árbol de cuya superficie será extraída su corteza y se procede a limpiar este contorno del tunu, quitando los bejucos, ramas y troncos que puedan enredar las herramientas que serán utilizadas para la tala del árbol, asegurando además que el trabajo se realice sin ningún peligro de que un miembro o compañero del grupo salga lesionado o herido.

2. Seleccionado ya y limpio el contorno del árbol se procede a una observación minuciosa para elegir el lado del corte, y que al tumbarlo caiga en dirección hacia dónde y cómo queremos. Con esto nos aseguramos que el lado de la superficie del tuno escogida para la operación de extracción quede cómodamente expuesta para tal fin. Esta técnica es parte de la sabiduría heredada de nuestros ancestros quienes desde entonces nos han enseñado que el tuno tiene su lado específico para hacer el pique en el tallo y facilitar así su extracción.

Tomado del texto: "Mujeres Mayangnas innovando el conocimiento ancestral sobre el tunu, fomentando una visión empresarial en el siglo XXI”. Organización de Mujeres Mayangnas MYRAB, Territorio Indígena Mayangna Sauni As. 2013. Financiado por FASOC IBIS Dinamarca. El texto tiene el propósito de documentar el uso ancestral y propiedad colectiva de la tela del tunu por parte de las culturas indigenas que habitan las zonas fronterizas entre Nicaragua y Honduras. De tal forma que el proceso de patente sea siempre una opción atribuible únicamente a estos pueblos. 
3. Una vez que el árbol está cortado y en el suelo, se mide su longitud y el espacio del cual se va a separar la corteza del tunu y se extrae una tira de corteza a lo largo de la superficie escogida para tal fin. Si se confunde el lado de extracción, nuestros sabios ancestros indicaban que habría que fijar nuevamente el centro o corazón del árbol, pues, según ellos, en dicha ocasión el núcleo del tunu o sea el corazón, no está bien centrado. Entonces se marca de nuevo y se extrae la tira del lado donde el núcleo está más cercano a la orilla o al borde del grosor del árbol.

4. Una vez extraída la tira de corteza se usa una herramienta rústica que servirá para desprender la corteza. Se trata de una especie de palo redondeado y alargado que se elabora del árbol de cedro macho, con una punta en uno de los extremos. Valga aclarar que la punta no se fabrica del mismo grueso que el del redondel del palo, sino que solamente su mitad, de manera que queda similar a una punta trunca o biselada o chaflanada.

5. Lista la herramienta se procede a extraer la corteza, en este caso se coloca la punta entre la corteza y la madera del tunu y se le aplica mucha presión hasta desprender la corteza. En este punto es que se logra la extracción de la corteza del tunu. Luego se despegan las capas de la corteza. Se sabe que la corteza posee al menos tres capas y su separación implica que los comunitarios trabajen sólo con sus manos y al hacerlo de esa manera estarán expuestos a la savia del tunu la cual es fuerte y mancha las manos. Esta etapa de extraer las capas se hace previo al traslado de la corteza extraída, de lo contrario no se podrá moverla por su peso. La forma de extraer las capas es la siguiente:

a) se extiende la corteza en el suelo;

b) se le dobla la punta "una cuarta" (medida designada por nuestros ancianos $y$ que corresponde a la distancia que existe -estirando la palma de la mano abierta- entre el extremo del dedo meñique - $\mathrm{o}$ del que le sigue- y el pulgar;

c) en el doblez se aplica un poco de fuerza y se marca levemente con una herramienta filosa hasta cortar la capa superior de la corteza y desprenderla un poco dejándola lista para el trabajo en conjunto;

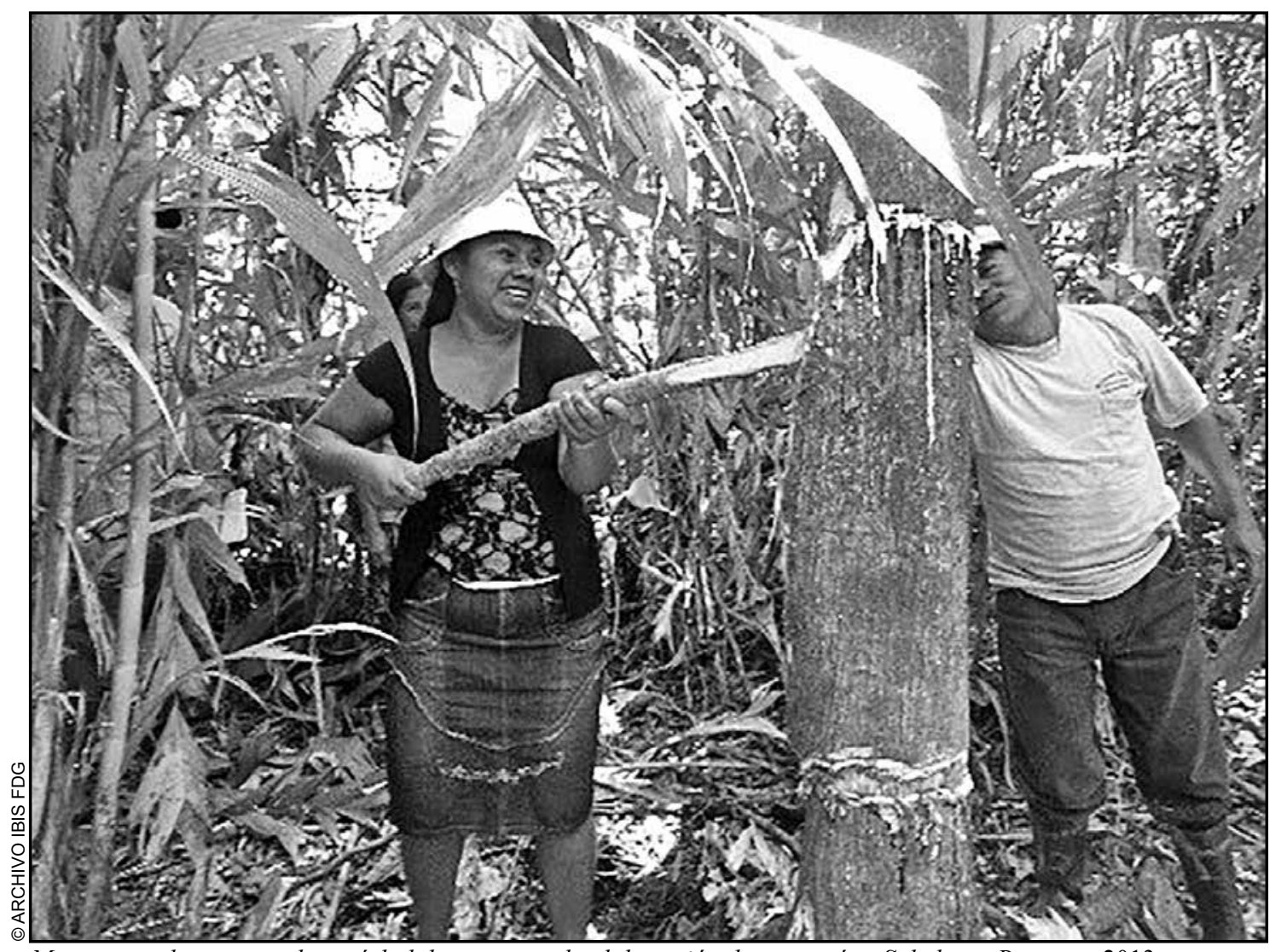

Mayangnas descortezando un árbol de tuno para la elaboración de artesanías. Sakalwas, Bonanza. 2013. 
d) luego se marca y corta entre dos personas quienes desprenden tanto la capa superior como la inferior, para lo cual una de las personas presiona la parte de abajo y la otra jala la parte superior.

6. Seguidamente se procede al procesamiento de la corteza del tunu, que también tiene pasos básicos a seguir y donde se requiere la utilización de dos herramientas rústicas, de madera y elaboradas ancestralmente de manera artesanal: el langlang $\mathrm{y}$ el para o tunidor. Se entiende por Langlang una superficie plana de madera larga donde se coloca la corteza de tunu para picar o procesarla. Por su parte el para o tunidor es elaborado en madera y con forma redonda (para mayo información ver también, en este mismo número de Wani, Rizo. 2017: XX). El tunidor o para sirve para picar o golpear la corteza del tunu. Esta corteza ya procesada recibe el nombre de âmat (tela) y su tradicional obtención artesanal requiere de seguir al pie de la letra el siguiente proceso:

a. Tomar la decisión de si el mismo día que se extrajo la corteza debe de ser procesada o se deja para el siguiente día. Esta decisión tiene que ver con el tipo o calidad del tono de âmat (tela) que desea obtener y para qué se usará.

b. Si la decisión es procesar hasta el siguiente día se deja la corteza en agua. Tomada la decisión se procesa la corteza con la aplicación de las dos herramientas rústicas, el langlang y el para) y a continuación se ubica la corteza encima del langlang y se comienza a golpear o picar con el para hasta convertirla en una tela suave $\mathrm{y}$ agradable al tacto.

c. El procesamiento de la corteza de tunu finaliza con el lavado de la tela, es decir, una vez que se logra adquirir la textura de la tela deseada se lava con delicadeza y bien y se pone a secar.

Tradicionalmente nuestros ancestros utilizaban sólo el tunu café (tikam), nuestra cultura se dedicó más a la extracción del tikam y más tarde y de manera espontánea se introdujo el uso y extracción del tunu blanco (yakautah). La extracción del yakautah implica un proceso muy delicado y aún más especializado que la extracción del tikam, debido a que su savia es tan

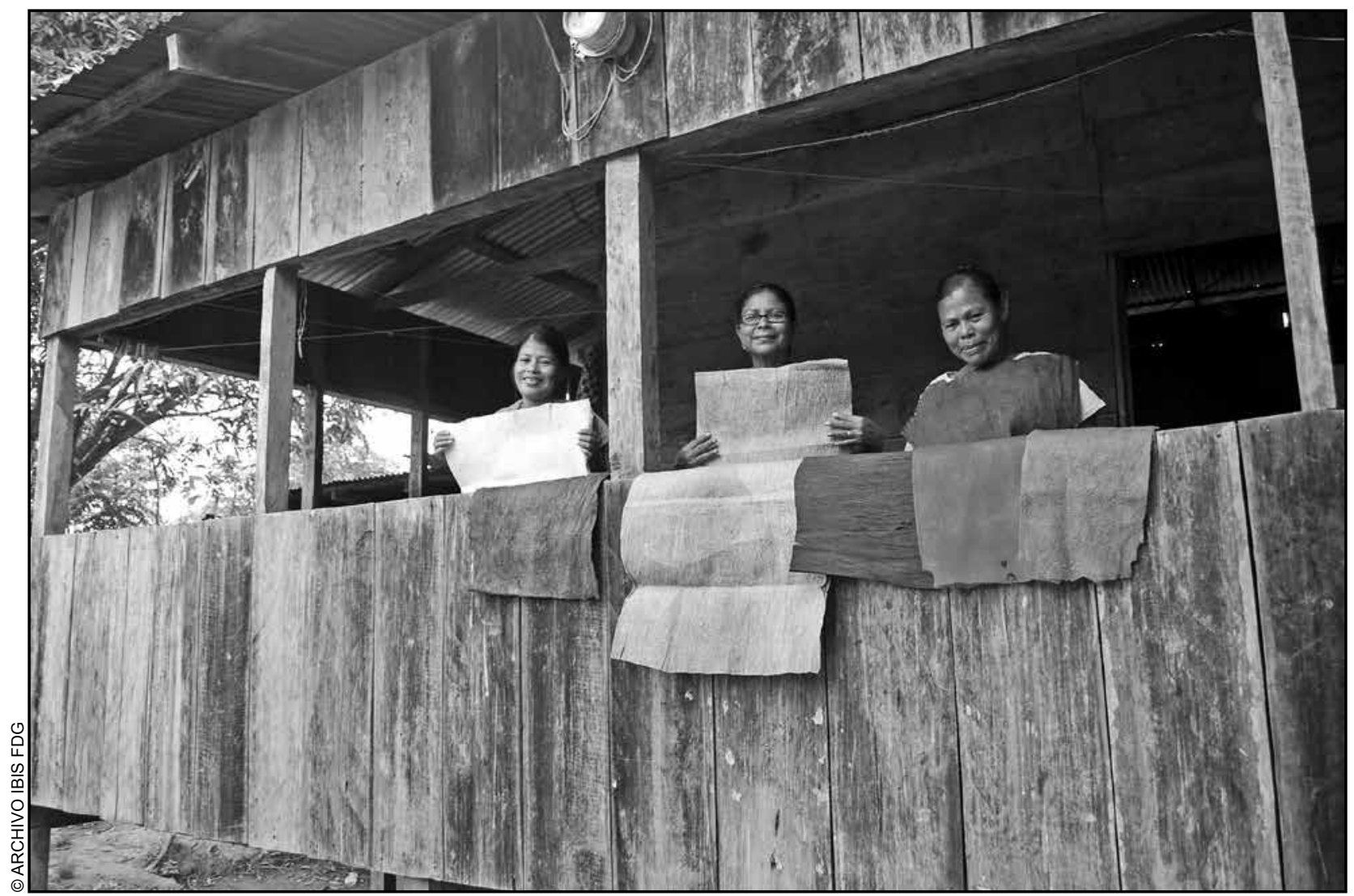

Mujeres artesanas mayangnas con materiales procesados del árbol de tuno. Sakalwas, Bonanza. 2013. 
fuerte que quema la piel de la persona que se dedica a este trabajo. Nuestros ancestros nos enseñaron a evitar las lesiones cutáneas con el uso del achiote en los brazos y mejías, y así evadían provocar alguna lesión o enfermedad cutánea. Antes de extraer la corteza del yakautah se pasaba por el fuego "soasando" la corteza, una manera de pasarla sin quemar para aminorar la composición de ácido contenida en el látex, que provoca las quemaduras de la piel; esto además aflojaba un poco la corteza permitiendo un fácil desprendimiento en la extracción.

\section{Innovación en la extracción de la corteza del tunu}

La Asociación MYRAB descubrió una nueva técnica para el proceso de extracción de la corteza de TUNU de una manera más ecológica. La innovación consiste en aprovechar el uso adecuado de esta reliquia cultural (Corteza del TUNU) extrayendo la corteza en pie. En la actualidad las mujeres socias de MYRAB extraen la corteza del tunu sin cortar el árbol. La finalidad de esta técnica consiste en aprovechar la materia prima de la corteza del árbol en pie y posteriormente cubrir el árbol para su regeneración, de modo que su corteza vuelva a regenerarse en un corto tiempo. Esta nueva técnica es propiedad intelectual de MYRAB, ya que fueron las mujeres de esta asociación quienes desarrollaron el proceso de regeneración de corteza, con mucho esfuerzo y dedicación, para fortalecer a la organización femenina MYRAB y las prácticas culturales de estas mujeres mayangnas. A esto se debe el lema que las mujeres han creado "Aprovechar el árbol de tunu es fortalecer la identidad del pueblo Mayangna, cultivando, conservando y construyendo el futuro".

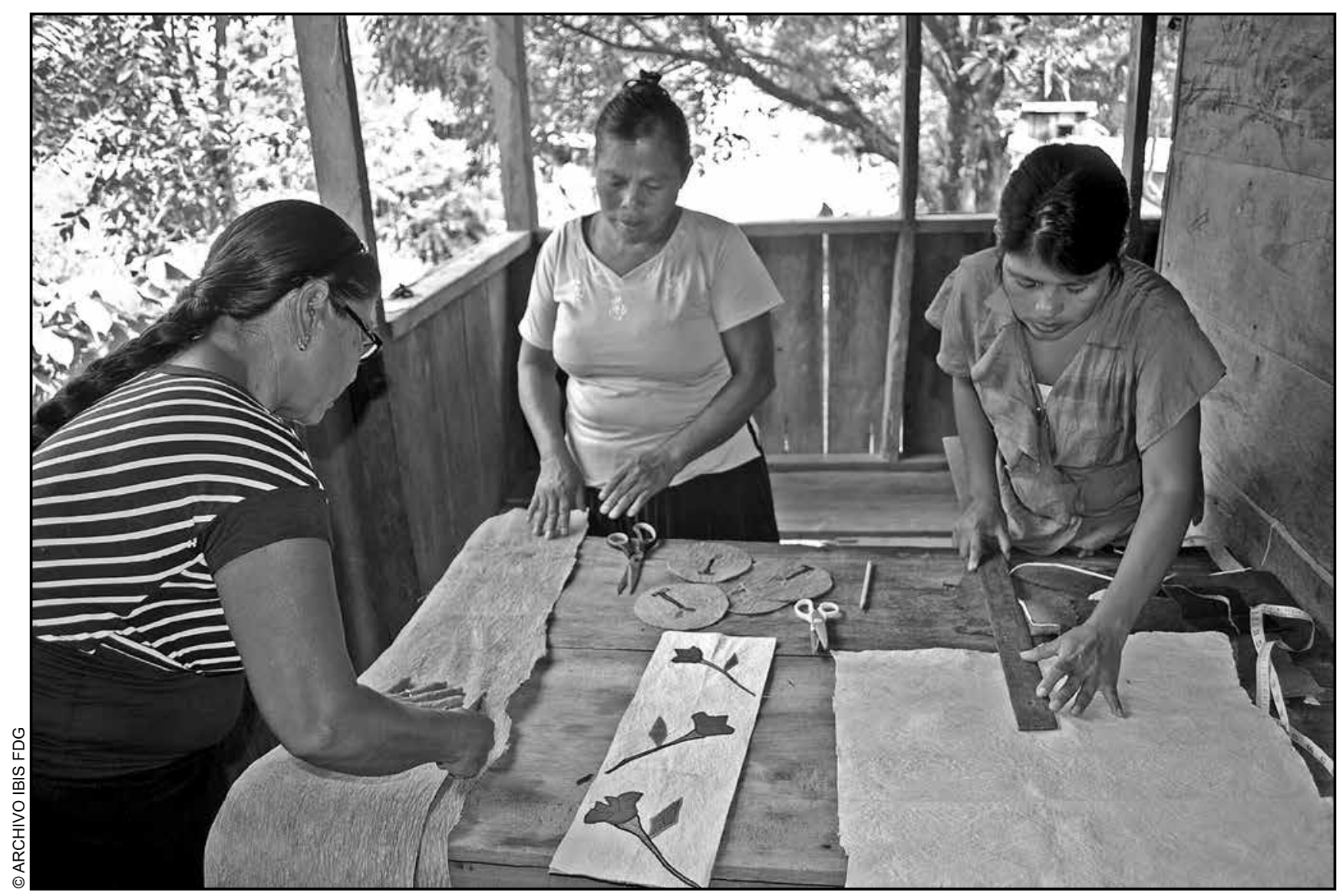

Elaborando artesanías con los materiales procesados del árbol de tuno. Sakalwas, Bonanza. 2013. 